Revista de Filosofía

ISSN: 0034-8244

https://dx.doi.org/10.5209/resf.65350

\title{
De la oscura potencia de lo femenino en el pensamiento de F. Schelling
}

\author{
María José Binetti ${ }^{1}$
}

Recibido: 21 de agosto de 2019 / Aceptado: 2 de marzo de 2020

Resumen. Nacimiento, concepción y gestación, huevo cósmico, rueda eterna, noche, caos y oscuridad abisal son algunas de las imágenes que Friedrich Schelling asume a los efectos de reconceptualizar la especulación y, en concreto, de desfundar y superar el paradigma falogocéntrico del Acto trascendente, perfecto y pura luz. La propuesta schellingiana de un fundamento inmanente y material, pura potencia indeterminada e infinita, supone una re-sexualización del discurso filosófico que intentaremos mostrar en estas líneas.

Palabras clave: caos; noche; nacimiento; fundamento; materia; devenir.

\section{[en] On the dark Potency of Female in F. Schelling's Thought}

\begin{abstract}
Birth, conception and gestation, cosmic egg, eternal wheel, night, chaos and abyssal darkness are some of the images that Friedrich Schelling assumes in order to reconceptualize speculation and, in particular, to unfound and overcome the phalogocentric paradigm of the transcendent, perfect and pure luminous Act. The Schellingian proposal of an immanent and material ground, purely indeterminate and infinite potency, implies a re-sexualization of the philosophical discourse that I will try to explain in the following lines.
\end{abstract}

Keywords: chaos, night, birth, ground, matter, becoming.

Sumario: 1. Introducción; 2. La feminización romántica de la filosofía; 3. Del Ser trascendente al poder inmanente; 4. Una potenciación dialéctica, ascendente y libre; 5 . La concepción de lo naciente; 6 . A modo conclusivo; 7. Referencias bibliográficas.

Cómo citar: Binetti, M.J. (2021): "De la oscura potencia de lo femenino en el pensamiento de F. Schelling”, en Revista de Filosofía 46 (1), 157-171.

1 CONICET - Instituto de Investigaciones en Estudios de Género, Universidad de Buenos Aires.

mjbinetti@gmail.com 


\section{Introducción}

La figura de Friedrich W. J. Schelling emerge en el horizonte especulativo de las últimas 3 décadas con una contundencia que su propia posteridad inmediata desconoció. Como por una suerte de reparación histórica, Schelling recibe hoy su merecido reconocimiento especulativo, una vez catalizado el efecto volcánico de Hegel, y repuesto de cierta mala reputación que lo tachara por volátil y lo rebajara a ser un paréntesis entre Fichte y Hegel. En una puesta al día de la historia, el pensamiento continental contemporáneo ve en Schelling al precursor del materialismo, el existencialismo, el psicoanálisis y la fenomenología de las religiones (Norman y Welchman 2004, p. 6).

El hecho de que a sus Lecciones de Berlín hayan asistido Friedrich Engels, Mijaíl Bakunin, Ludwig Feuerbach, Arnold Ruge y Søren Kierkegaard, entre otros, muestra de suyo la encrucijada histórica en la que se ubica el pensamiento de Schelling, en el auge de un post-hegelianismo cuyo viraje material y existencial lleva la impronta schellingiana. Acompañados por el último Schelling de Berlín, los jóvenes hegelianos de izquierda retornaban a las raíces románticas del idealismo, por oposición a un Hegel que era representado como el adalid de la racionalidad abstracta del concepto. La filosofía positiva de Berlín se abocaba a interpretar la materialidad viviente de la naturaleza, la facticidad de la existencia, la contingencia del devenir, el mito y la revelación histórica, todo lo cual parecía abrir un atajo en el bloque inexpugnable del sistema hegeliano.

Slavoj Žižek ubica a Schelling en el origen del materialismo dialéctico en alusión tanto a la primacía de la materia como potencia irreductible a toda actualización, como por la persistencia de un resto no-pre-pensable irreductible a la razón (Žižek 1997, p. 33; 1996, p. 7; Gratton 2014). A esta fuerza vital inagotable e irreductible remiten también las eco-filosofías y ecofeminismos, muchas de las cuales derivan de Schelling el carácter autopoiético, subjetivo y social de la naturaleza (HollandCunz 1996; Grant 2006; O’ Neill Burns 2016). En el caso del existencialismo, la impronta schellingiana procede directamente de la participación de Kierkegaard en las Lecciones de Berlín, donde conoció de primera mano la diferencia entre el quid sit y el quod sit, la esencia y la existencia de lo real (Binetti 2015; Assiter 2015). El psicoanálisis, por su parte, hereda de Schelling la afirmación de un inconsciente oscuro, abisal e impenetrable que opera en la existencia como voluntad no-prepensable -pulsión o deseo- creadora y devoradora a la vez (Fenichel 2019, pp. 3 ss.; Wirth 2005, p. 43). Por último, la expresión mítico-especulativa que Schelling reclama para esta fuerza en sí inaccesible replica en las filosofías y fenomenologías de la conciencia religiosa, la posición de un mal radical y la experiencia de la inconmensurabilidad del Otro.

En el marco de la renovada vigencia que goza actualmente el pensamiento schellingiano, la propuesta de este artículo consiste en atender la in-determinación sexual o sexuada de esa oscura potencia de lo negativo que des-funda el devenir y que Schelling califica, concretamente, como femenina. Dicho de otro modo, nos proponemos mostrar que la ruptura y renovación romántico-idealista y en particular schellingiana del pensamiento moderno es inherente a la resignificación de la diferencia sexual y, a la postre, concomitante con la exigencia de transformar el estatus socio-político de las mujeres. Con esto no pretendemos hacer de Schelling un pensador feminista o proto-feminista -tipificación que por lo demás nos resulta 
carente de interés-, sino más bien mostrar aquellos elementos de su filosofía que implican la re-sexualización del discurso filosófico, reconceptualizan lo femenino como energía generadora inmanente y logran de ese modo superar el paradigma falogocéntrico de una trascendencia sustancialista, clara y perfecta. En tanto y en cuanto el paradigma romántico en general y schellingiano en particular quiebran la tradicional asociación de lo femenino con una materialidad meramente pasiva, receptiva, degenerante y corruptora de la perfección formal para restituirlo a su potencialidad creadora, podemos vincular tal paradigmas con el nacimiento histórico del feminismo como movimiento socio-político.

\section{La feminización romántica de la filosofía}

Entre el viejo régimen teo-céntrico, justificado metafísicamente por el Acto puro y trascendente, y sostenido por la heteronomía de la ley moral, y el nuevo régimen de la mayoría de edad socio-política, justificado por la inmanencia dinámica de lo absoluto y la autonomía de la libertad, ambos, se juega la suerte de la Revolución. La atmósfera de la Revolución, en la cual anidan los grandes ideales de libertad e igualdad, es también el comienzo de la lucha feminista como tradición teóricopolítica, nacida y justificada por el pensamiento de la Ilustración. En efecto, el proyecto moderno de igualdad y libertad individual cobijó la primera ola del feminismo Ilustrado, que podríamos ubicar entre De la igualdad de los sexos de François Poullain de La Barre (1673) y La reivindicación de los derechos de la mujer de Mary Wollstonecraft (1792), entre los cuales se entretejen los esfuerzos de Voltaire, Montesquieu, D'Alambert, el Barón D'Holbach o Condorcet por incluir a las mujeres en el proyecto democrático. El hecho de que la Declaración de los derechos de la mujer y de la ciudadana de Olympe de Gouges (1791) y, en general, la Revolución misma desembocaran en un dramático final, no obsta el hecho de que los principios de libertad, autonomía individual e igualdad de derechos cívicopolítico fueran entonces asentados de una vez para siempre y continuaran alimentado las demandas de una revolución permanente.

Romanticismo e idealismo alemanes acogen y renuevan el espíritu de la revolución, en un intento por superar lo que consideraron las causas de su fracaso, a saber, el intelectualismo abstracto del Iluminismo y la falta de una comunidad estético-religiosa, carencias que desembocaron en el nihilismo, el terror y la incapacidad de legitimación social. La renovación y justificación ontológica del proyecto revolucionario constituyó el ideario del primer romanticismo alemán del Círculo de Jena -el Frühromantik-, que se interpretó a sí mismo como el espíritu de la revolución y elaboró una ontología de la libertad individual en tanto que sujeto absoluto. Así como el Iluminismo no pudo dejar de cuestionar el estatus sociopolítico de las mujeres, el nuevo iluminismo alemán tampoco pudo evitar la realidad de lo femenino como dimensión fundamental de su proyecto emancipador. Más aún, fue específicamente la realidad de lo femenino la que le posibilitó al romanticismo abandonar el viejo paradigma intelectualista a fin de instaurar un nuevo modelo poético-especulativo, que encuentra en lo femenino la vena antirracionalista, estético-afectiva, material y dinámica capaz de sublevar al pensamiento contra su propia fundamentación sustancialista. 
Nos remitimos en este punto a Lisa C. Roetzel Lisa (Schulte-Sasse 1997, pp. 359462) quien considera que hay en el romanticismo una «feminización» de la filosofía, en virtud de la cual se hizo posible la crítica al modelo tradicional y la defensa de la libertad como esencia - no ya propiedad facultativa- absoluta. El Círculo de Jena declara femenina a su filosofía (Schulte-Sasse 1997, p. 362) e incorpora mujeres a sus debates, por considerarlas sujetas dignas de reflexión y conocimiento, cosa absolutamente revolucionaria para su tiempo. La idea de que la filosofía es femenina responde a un viejo arquetipo prehistórico, según el cual la sabiduría, el arte y la religión eran privilegio de las mujeres, en particular de las mujeres mayores o madres de las madres (Binetti 2018, pp. 146 ss.). La reposición romántica de esta idea, después de milenios de patriarcado filosófico y cultural, es consistente con la refundación del pensamiento en la libertad.

Con esto no pretendemos clasificar al romanticismo dentro de los movimientos feministas ni mucho menos. Por el contrario, este reproduce muchos de los estereotipos de género de la tradición patriarcal. Sin embargo, aun cuando tal sea el caso, tal reproducción se produce en una nueva atmósfera intelectual que quiebra los supuestos del viejo régimen y sienta las bases para la resignificación de lo que aquel tenía por negativo y degradante. Ciertamente, el romanticismo da por supuesta la clásica tabla de oposición entre lo masculino -lo uno determinante, perfecto, idéntico, activo, recto, luminoso, racional, bueno, seco y reposado- y lo femenino -lo impar indeterminado, imperfecto, diferente, pasivo, torcido, oscuro, irracional, malo, húmedo y móvil-. No obstante, a la par que la reproduce, también desfonda el paradigma del Uno inmóvil, acabado y luminoso, sustituyendo la trascendencia absoluta por una dialéctica inmanente de la finitud. Esto supone, por primera vez en la historia de la especulación, la posibilidad de interpretar la diferencia sexual por fuera del dualismo entre lo Uno inconmensurable, espiritual y perfecto - lo masculino- y la díada indefinida, material, oscura de la feminidad. Supone, dicho en otros términos, la posibilidad de pensar la dualidad sexual fuera del dualismo sustancialista, la diferencia fuera del modelo de la identidad abstracta, la inteligibilidad fuera del intelectualismo y lo originario a partir de una dialéctica inmanente y reflexiva.

Si hasta el romanticismo, siguiendo a Alison Stone (2018), el modelo de la sexuación fue el de Un solo sexo -idéntico y excluyente- y su degradación, a partir de entonces los sexos serán dos y el dos, una dialéctica creadora. El abandono del Acto perfecto como origen trascendente e incomensurable obligó a la resignificación de todas aquellas nociones que aquel mismo medía con su perfección inmaculada y que emergen ahora transmutadas, en un horizonte de inmanencia radical. Nos referimos puntualmente a nociones tales como materia, negación, potencia, noche, oscuridad, sublimidad y misterio, fantasía, arte, poesía y mito, que pasan a ocupar así el centro generador de la escena filosófica, en analogía con lo femenino y en consonancia con una agenda revolucionaria.

El ideal intelectualista y contemplativo del saber filosófico deja lugar a una praxis activa de conocimiento, que asume el modelo creador del arte y la poesía, asociado además a una suerte de re-sexualización de la filosofía como significante de su crítica y aspiraciones transformadoras. Los motivos y figuras literarias del fragmento, la novela, las cartas, la ironía, el chiste, la sátira o el sarcasmo le abren paso a una vanguardia que quiebra las formas tradicionales de contemplación y re-presentación a fin de crear nuevas presentaciones de verdad que las formas artísticas viabilizan. En el mismo sentido, la idea de un sujeto pensante autoidéntico e inmediato -sustancial, 
claro y distinto- es superada por el dinamismo inmanente y medial -dialéctico, diferencial y negativo- de la subjetividad libre y creadora.

A título ilustrativo, quisiéramos mencionar dos grandes obras de este período que valen como hitos poético-especulativos de la ruptura y transformación señalada, a saber: la Lucinda de Friedrich Schlegel y los Himnos a la noche de Novalis. En el caso de F. Schlegel, el romanticismo quizás tenga en él al crítico más comprometido de la opresión de las mujeres, defensor de su igualdad y participación en una symfilosofía producida en el intercambio recíproco entre varones y mujeres. Schlegel ve en las mujeres la fuerza renovadora capaz de devolverle a la época su salud espiritual (Schlegel 1994, p. 166). En su Teoría de la feminidad, él asegura que "el espíritu es lo original femenino. Y, por lo tanto, reflexión o, mejor aún, fantasía. El objeto es masculino, el sujeto femenino" (Schulte-Sasse 1997, p. 398). Con la atribución de subjetividad y individualidad a las mujeres, Schlegel justificaba su igualdad de derechos y el acceso a una emancipación que, en los términos del idealismo romántico, nunca es solo política, sino fundamentalmente estética, filosófica, moral y religiosa. No solo son indispensables a las mujeres los derechos políticos y civiles, sino también la filosofía, que constituye en rigor su necesidad más inmediata (Schlegel 1994, p. 70, 82-83, 86). La introducción de las mujeres a la producción filosófica y de lo femenino -sinónimo de reflexión, fantasía y subjetividad- en la génesis del conocimiento, eleva a este último a la dimensión poética, que es el registro por antonomasia del absoluto romántico. Para la mujer "su propio ser es poesía" (Schlegel, 1994, p. 166) y por eso a través suyo el romanticismo acceda a la libertad creadora, su órgano de conocimiento especulativo.

Lucinda, el gran bildungsroman de Schlegel (2007), contiene a un ideario de igualdad y liberación de las mujeres a partir de la sexualidad en el amplio sentido de un erotismo vital y creador: "sensual beatitud", "voluptuosidad del espíritu", "fuego sagrado de la divina pasión" (Schlegel 2007, p. 17). La aparición de la novela -un siglo antes de que Freud reivindicara lo sexual como pulsión de vida- produjo un escándalo en los ambientes más más tradicionales y moralistas de la época, incluso en el propio Hegel, mientras que fue celebrada por la Joven Alemania como un evangelio de rehabilitación de la sensualidad (Kierkegaard 2000, p. 307). La obra buscaba despertar indirectamente a través de historia de amor de sus protagonistas -Lucinda y Julio Antonio- la propia subjetividad individual del lector, elevarla a la dignidad de lo divino inmanente, consumar su fuerza autocreadora, y entregarla a la infinitud del amor y la libertad que son su esencia absoluta. En el dominio de ese juego creador abierto por la fantasía libre e infinita, lo femenino ofrece el modelo de una intimidad capaz de dar a luz y cobijar la diferencia absoluta en la reciprocidad del amor. Si el romanticismo vio en el vínculo amoroso el paradigma de una identidad medial y diferenciada, este encontró en la feminidad, para la cual amar y vivir son la misma cosa, el modelo supremo de esa unidad (Schlegel 2007, p. 10).

En el caso de Novalis, su pensamiento confirma a la mujer como sujeto espiritual, "símbolo del bien y la belleza" (Novalis 2007, p. 127), cosa que, respecto de la tradicional asociación de las mujeres con la fealdad, lo torcido y el mal, supone una subversión ideológica, motivo incluso de cierto misticismo cultual. Los Himnos a la noche profundizan la transmutación con la consagración de lo oscuro, abismal, negativo y mistérico como instancia activa de generación y transformación, en consonancia con aquellos tiempos prehistóricos cuando las divinidades lunares y sus ciclos eternos guardaban el secreto de toda creación y destrucción. La noche 
de Novalis es símbolo de muerte, vacío informe, indiferencia absoluta, apeiron misterioso, inaccesible e impronunciable por ausencia de todo límite y determinación. $\mathrm{Su}$ novedad especulativa reside propiamente en la potencialidad inmanente que Novalis le atribuye a esta negatividad radical, la cual, a diferencia de la metafísica clásica, ya no permanecerá opuesta y excluida extrínsecamente de lo positivo, sino que se convertirá ella misma en origen creador, primer principio de vida, esencia y verdad de todas las cosas (Schlagdenhauffen 1934, p. 395). La noche sueña, inspira y concibe, su seno infinito gesta y alumbra todo despertar; ella es la nada de la creación una vez depuesta la trascendencia solar del Acto perfecto. Con la noche de Novalis vuelve aquel tiempo inmemorial en que el Caos estaba al comienzo de una teogonía mítico-poético, no temporalizable ella misma y sin embargo temporalizadora de toda experiencia (Albizu 1995, pp. 68 ss.). La figura de la noche condensa el desfondamiento de la causa primera, perfecta y sustancial, y su sustitución por un seno infinito en continua gestación universal.

La retracción inmanente del Logos puro al mito imaginario, de la contemplación intelectual a la creación poética, de la luminosidad perfecta a la oscuridad agónica y abisal, de la trascendencia del ser a la inmanencia del devenir, del acto puro masculino a la indeterminación femenina enmarca el desafío romántico a la tradición falogocéntrica y su apuesta revolucionaria. El giro especulativo del romanticismo no es abstracto sino concreto, material y sexuado, y ese valor de sexuación se apoyó en el origen y elemento femenino del pensar para justificar la revolución estética, religiosa, moral y política que el romanticismo quiso ser, una revolución que atendió ante todo a la subjetividad singular.

\section{Del Ser trascendente al poder inmanente}

Friedrich Schelling perteneció el Círculo de Jena, compartió su proyecto emancipador y expresó en sus propios términos lo que interpretaré en las siguientes páginas como el paso atrás -pre-histórico y pre-intelectual- del pensamiento hacia la noche mítica de su concepción. En Jena conoció a Carolina Schlegel, con quien se casará en 1803 y a quien acompañará hasta su muerte. Si el pensamiento de Novalis no es concebible sin la reciprocidad amorosa de Sofia, ni el de Hölderlin sin la libertad infinita de su vínculo con Diotima (Hölderlin 2009, I, p. 91), tampoco Schelling es pensable sin la pulsión vital que lo unió a Carolina.

Schelling fue consciente de su posición histórica y del cambio de signo que su época representaba. Él mismo alude a esto en los siguientes términos: "fue una bella época aquella en que esta filosofía surgió, cuando por medio de Kant y Fichte el espíritu humano se afianzó en la verdadera libertad frente a todo ser y se sintió autorizado a preguntar no ya ¿qué existe? sino ¿qué puede existir?" (Schelling 1998, p. 110). Del ser al poder se juega para Schelling tanto la suerte de la libertad subjetiva como el futuro de la filosofía. A la concepción de este poder dedicaremos las siguientes páginas, resaltando su oscuridad por oposición a la luminosidad del Logos clásico. Si bien no se encuentra literalmente en Schelling la metáfora "oscura potencia" que titula este artículo, entendemos que su imagen es consistente tanto con el espíritu del romanticismo en general como con esa progresiva y ascendente diferenciación que determina a lo posible. Si es válido llamar a Hölderlin un poeta solar, encandilado por un ascenso indetenible, valga considerar a Schelling -su 
inseparable compañero de Tubinga- el pensador de lo más hondo y oscuro.

Potencia, poder, posibilidad infinita son categorías centrales del pensamiento schellingiano, en las cuales su autor cifra la transmutación especulativa de su tiempo. El desplazamiento de la pregunta por el ser y lo sido, a la pregunta por el poder y lo posible opera en Schelling la des-fundación del viejo paradigma sustancialista y representativo, en orden a la re-fundación inmanente de la libertad creadora. Estrictamente hablando, la potencia constituye una categoría reflexiva o autorreflexiva del ser, esto es, su propio desdoblamiento por el cual la inexorabilidad del factum resulta contingente y relativa. Lo posible es para Schelling el ser mismo en su carácter reflexivo, dinámico y contingente. Y con esta categoría él introduce una suerte de reduplicación en lo absoluto mismo, habilitando así su transitividad a lo finito.

En efecto, si la antigua metafísica del Esse subsistens afirmó la inexpugnable unidad del Acto puro, trascendente a toda finitud, el concepto de potencia supone un desdoblamiento de lo absoluto que Schelling describe como el pasaje del Uno trascendente al fundamento de la existencia de Dios, esto es, de su Inmutabilidad inaccesible a su querer o voluntad de extrañamiento. El dualismo que el Esse subsistents establece entre sí mismo y el mundo, Schelling parecería trasladarlo al absoluto mismo quien, por una suerte de contracción originaria, pone la diferencia entre su Unidad Infundada y el fundamento divino (Schelling 1989). En palabras de Schelling, Dios es inmanencia devenida trascendencia (Schelling 2007b, p. 209), o bien, Esse deviene poder.

El In-fundamento -Ungrund y Urgund- es pura identidad, incondicionalidad e indiferencia absoluta que precede todo fundamento, existencia y dualidad, y permanece separado de toda oposición a la manera de "resto" (Schelling 1989, p. 169) que equivale al "no-ser" (Schelling 1989, p. 281) de toda diferencia. De su negatividad se desprende su carácter de no-pre-pensable, análogo a aquella "noche oscura" (Schelling 1989, p. 169) de la que nace toda luz. Razón y pensamiento son productos de esa oscuridad impenetrable a su efecto. El resto está siempre presente como retracción o latencia, activo, pero no activado (Carrasco-Conde 2019, p. 13), su presencia es operacional y reguladora, pero nunca constitutiva inmanente. El fundamento divino, por su parte, resulta de la negación reflexiva del anterior y comporta una suerte de vaciamiento ontológico a partir de la cual es posible crear. También el fundamento es oscuridad indecidible, caos o vacío abismal del cual emerge todo en la medida en que "el fundamento eternamente oscuro que no es actu él mismo" (Schelling 1989, p. 163), sino potencia infinita de ser.

A los efectos de explicar la negatividad reflexiva del fundamento, Schelling apela a la noción de "retracción" o "contracción" de Dios (Schelling 2002) a la cual le sucederá su partición o parición de la existencia. El In-fundamento no se niega en sí mismo sino en otro, a saber, en ese fundamento que será necesariamente la noidentidad o diferencia de lo absoluto, potencia y posibilidad de existir fuera de lo Uno, en la continuidad del devenir. La negatividad del fundamento divino media la posición de la existencia finita por la mediación de lo absoluto mismo, derivado de su propia negatividad. La idea de una "divinidad derivada" (Schelling 1989, p. 139) transforma el paradigma metafísico de la trascendencia causal ex nihilo -asegurada en la linealidad unidireccional de la causa al afecto- por una suerte de circularidad auto-causal -la causa sui de todos los monismos- que actúa recíprocamente sobre la divinidad misma. Es decir que el Uno infundado anterior al fundamento resulta a 
la vez engendrado por este (Schelling 1989, p. 165), en el círculo de un movimiento reflexivo que refracta siempre aquel resto inaccesible a toda creación. La derivación -emanación- divina salva lo absoluto de un eterno inmovilismo abstracto, a la vez que deja incólume ese resto del cual se alimenta.

Lo específico de ese desdoblamiento del Uno infundado al fundamento divino, o bien del Acto a la posibilidad infinita, consiste en la libre decisión de lo absoluto, fruto de su ansia de engendrarse a sí mismo (Schelling 1989). Dicho pasaje es obra de la libertad y el anhelo creador de lo divino, con lo cual Schelling busca quebrar la inmediatez sustancialista del panteísmo spinoziano, garantizar la personalidad de Dios y desfondar la inexorabilidad causal de la realidad finita, fundada ahora en la libertad del poder. La introducción del deseo en el movimiento reflexivo, es decir, de la libertad o el querer en la estructura reflexiva misma, es una premisa romántica que Schelling continúa - como lo hará también a su modo Hegel con la autoconcienciay sobre la cual descansa la constitución libre del sujeto. La posibilidad desfonda de ese modo a la sustancia clara, distinta e inmediata, replanteando el fundamento como voluntad libre y contingente.

Entre el Uno infundado y el fundamento de la existencia, lo que media es poder, potencia o posibilidad infinita, porque según Schelling "un ser no puede negarse a sí mismo como real sin al mismo tiempo ponerse como la potencia generadora y realizadora de sí mismo" (Schelling 2002, p. 187). La potencia es así una categoría reflexiva, negativa y creadora: "no-ente", "negación originaria" (Schelling 2002, p. 183) y fuerza de creación, "pues solo en la negación reside el comienzo" (Schelling 2002, p. 185). Sin embargo, se trata aquí de una negación específica, algo así como un medium entre Infundado y el devenir finito que desmiente tanto al Uno como a la nada pura. Žižek la denomina en este sentido una nada "menos que nada" (2014, p. 342), descrita por Schelling como "algo medio entre lo que es y la nada: lo que no es ni debe ser, pero intenta ser” (Schelling 2002, p. 212). La ambigüedad o duplicidad de una nada que quiere libremente ser, pero no es ni debe ser, constituye la marca de un origen él mismo escindido, tensionado y contradicho.

Dispuesta en el origen de todas las cosas, la negatividad de lo posible determina el carácter contradictorio de lo real, su incesante pasaje de ida y vuelta del no-ser al ser, en una palabra, su devenir esencial. Por principio, lo real se contradice a sí mismo, su acción desmiente la nada que lo funda y en esa tensión insiste su existencia. Por eso para Schelling "toda vida ha de pasar por el fuego de la contradicción; la contradicción es el motor de la vida, lo más interior a ella” (Schelling 2002, p. 244). Si el Acto perfecto trascendente se instituía en fundamento de sustancias autoidénticas, claras y distintas, en cambio la potencia negativa des-funda la existencia, oscurece su origen, la sujeta a una progresión infinita de lo indeterminado a la determinación $\mathrm{y}$, en última instancia, la restituye a la nada de la cual surgió.

La filosofía de Schelling es así una filosofía del devenir en el sentido de una progresión ascendente del no-ser al ser. Este carácter esencialmente genésico responde a la superación del Ser por el poder, del Acto a la potencia que libremente ha decidido dar a luz. De lo dicho hasta aquí, aquello que puntualmente nos interesa subrayar es que esa transmutación ontológica respecto del viejo sustancialismo metafísico implicó cierta feminización o re-sexualización del discurso filosófico. En efecto, mientras que el modelo del Esse puro y perfecto resultó consustancial al falo-logos-onto-teo-centrismo, el giro romántico-schellingiano quebró el paradigma masculino de la racionalidad clara y distinta, para sustituirlo por una 
oscura potencialidad pregnante, imagen de aquel mítico pre-tiempo caótico, abisal y matricial. En palabras de Schelling, "aun hoy aquella negación originaria es la madre y la nodriza de todo el mundo visible para nosotros” (2002, p. 197). El arquetipo de la concepción, gestación y parición viene así a superar el paradigma de la trascendencia eyacular, erigida por encima de todas las cosas. La potencia vital ya no será insuflada desde afuera ni descendida de lo alto ni dirigida a la Causa final, sino gestada desde adentro, alumbrada por una oscuridad radical y vuelta a parirse una y otra vez (Schelling 2002, p. 189).

La re-sexuación del pensamiento schellingiano es explícita. Fundamento, potencia, materia y razón son femeninas; acto y entendimiento son masculinos (Schelling 1998, p. 97). En su intento de una síntesis entre idealismo y psicoanálisis, Žižek ha destacado la incidencia de la diferencia sexual en la filosofía de Schelling y su interpretación femenina del fundamento (Žižek 1997, pp. 7, 10). Según Žižek, lo femenino schellingiano reside en la negatividad de una potencia continuamente se determina a sí misma y que Žižek identifica con aquel resto indivisible que hace imposible cualquier clausura totalizadora (Žižek 2017, p. 143). Lo femenino restituye el origen a la oscuridad abisal de la potencia, a la noche del engendramiento, a la materia y su parto sagrado, al mito y su eterno secreto (Žižek 1997, p. 10; 2017, p. $143)$.

\section{Una potenciación dialéctica, ascendente y libre}

El fundamento de la existencia es la decisión divina, su libertad, de convertir la necesidad de su esencia eterna en posibilidad de devenir finito y temporal. Esta posibilidad o potencia infinita - dynamis, potenz-constituye el trasfondo sobre el cual se elevan todas las cosas, que Schelling describe como una capacidad incondicional e indeterminada, dispuesta ómnibus aequa -a todo por igual-. La potencia contiene implícitamente su despliegue temporal y por eso ella mira hacia el futuro, al acto -actus, wirkung- o lo hecho siempre en los términos de lo particular y contingente, cuya facticidad la potencia prioriza como una esencia universal, libre y genésica. A los efectos de explicar el despliegue o expositio de lo potencialmente implícito, Schelling propone una organización interna de potencias sucesivas y en progresión ascendente que constituyen la estructura dialéctica de todo devenir (Schelling 2007b, p. 142).

El devenir schellingiano consuma una potenciación ascendente que avanza del fondo oscuro e indeterminado de la materia a la transparencia luminosa de lo espiritual jalonando una progresión continua donde "cada estado precedente es fundamento, madre, potencia alumbradora del estado siguiente" (Schelling 2002, p. 208). El concepto de potenciación -Potenzierung-nombra en Schelling un proceso de diferenciación sucesiva y, por así decir, acumulativa y expansiva de lo posible. Las potencias son para Schelling "determinaciones ideales" (1999, p. 366), es decir, formas del movimiento capaces de multiplicarse por su propia flexión negativa. El hecho de atribuir a la potencia un valor ideal y, viceversa, a la idea un valor potencial convierte la misma inteligibilidad de las cosas en su propia virtualidad inmanente, cosa que eo ipso supera la abstracción metafísica de lo ideal por la concreción del devenir que su potencialidad reclama. En otras palabras, potenciación es la vez la ideación en la cual se produce la verdad como proceso auto-generador, en el que cada 
momento tiene como verdad el posterior. Porque la/s potencia/s es estructuralmente reflexiva -en lugar de la inmediatez sustancial y lineal que la excluye del acto- su acción refluye sobre ella misma habilitando un devenir ininterrumpido. Cada acto retorna a su origen potencial en el círculo de una repetición infinita, que es progresiva diferenciación creciente.

La dinamología schellingiana establece una dialéctica de poderes sucesivamente explicitados, que comienza en la potencia negativa o sujeto -poder ser, posibilidad, indeterminación, materia-, se enfrenta con la potencia positiva u objeto -tener que ser, necesidad, determinación, causa eficiente- y se resuelve en la potencia positivonegativa-deber ser, finalidad, autodeterminación- cuya estructura sintética concilia sujeto y objeto, posibilidad y necesidad, indeterminación y determinación. Schelling compara el pasaje de la materia indeterminada a la diferenciación actual con una progresión de la tesis a la antítesis (1996, p. 162) que descompone la materia en fuerzas opuestas y las expone a una continua contradicción. La síntesis final repite el estado de in-diferencia inicial mediado esta vez por la posición de la diferencia o contradicción. Tesis, antítesis y síntesis estructuran el devenir permanente de la existencia en la continua superación-reposición de fuerzas contrarias, mediadas por el sustrato siempre posible de su identidad.

La instancia primera y primordial de ese dinamismo potenciador ascendente es la materia -Urstoff-, sustrato y sujeto in-diferente que Schelling compara con el puro éter, el vacío, el caos abierto a la totalidad del ser. La materia constituye el Inbegriff compendio- de todas las posibilidades, dispuesta omnibus aequa -a todo por igual-, tanto al ser como al no ser. Su potencialidad es eterna, infinita e inagotable, con el único límite de su propia determinación inmanente, esto es, de su autodeterminación libre. La infinitud de la potencia primordial no es lineal -pasaje directo e inmediato de la potencia al acto--, sino antes bien circular en cuanto que el acto vuelve sobre su propia potencia potenciándola a un nuevo dinamismo siempre superior. Precisamente en razón de su indecidibilidad radical, la materia es condición de diferenciación o separación - diremption - entre fuerzas opuestas: contracción y expansión, negación y afirmación, posición y eliminación. La separación oposicional de fuerzas constituye un movimiento reflexivo por el cual la virtualidad implícita explicita su poder en la parición y partición de sí mismo.

Si bien la categoría schellingiana de materia retoma gran parte de sus atributos tradicionales -sustrato primordial, posibilidad, indeterminación, negatividad, vacío, oscuridad, madre y nodriza-, a la vez subvierte esa tradición restituyendo la consistencia autoactiva y genésica de la materia. En efecto, mientras que el pensamiento falogocéntrico interpretó la materia como pasividad receptiva, limitante y degradante de la pureza del acto generador, Schelling entendió que su tarea especulativa consistía en restituir "la esencia y dignidad de la materia" (Schelling 2005, p. 255; Binetti 2019), superando el paradigma dualista que la redujo a continente receptor y devolviendo a la materia su fuerza generadora. Para Schelling, la materia es "lo oscuro mismo" (1996, p. 53; 1989, p. 181), pero esa oscuridad es la potencia absoluta capaz de engendrarlo todo en la inmanencia de su seno infinito e insondable. Seno que en la contingencia de su parición será también tumba y renacimiento.

La restitución mítica del pensar y, recíprocamente, la restitución especulativa del mito expresa el desafío conceptual a la primacía falocéntrica del Logos puramente inteligible propio del romanticismo en general y de Schelling en particular. Mucho 
antes que el Intelecto clásico se encumbrara en medida de toda forma y acción, eran el Caos $-\chi \alpha \omega / \chi \alpha \imath v \omega-$ apertura y parición, y la Materia $-\gamma \alpha \omega / \gamma \varepsilon \gamma \alpha \alpha-$ menstruum universalis que todo lo forma y transforma. Y entre ambos fue Eros - $11 \rho \omega-$, la síntesis, lo tercero de la unidad, el pulso vital y creador (Schelling 2007a, pp. 30-31). La Teogonía de Hesíodo introduce aquel pre-tiempo nocturno y abisal, que fecunda y guarda el misterio de la existencia. Oscuridad de la caverna platónica, de la vida intrauterina, de lo inconsciente, los sueños y la nostalgia, angustia de una infinita posibilidad que siempre nace negada.

Porque la materia es principio autoactivo y genésico, la naturaleza que Schelling concibe es sujeto creador, agente de una potenciación ascendente y dialéctica en continua tensión, contracción, expansión y renacimiento. También la naturaleza se escinde en su propia reflexión, de la cual resulta su posición -para seguir la denominación spinoziana- como Natura naturans, indiferenciada, incondicional y autoproductora, y Natura naturata, diferenciada y devenida, la primera de las cuales no deja de traspasar a la otra y esta última, de retornar a la identidad de la cual fue arrancada (Schelling 1996, p. 179). La forma del movimiento, su idealidad o posibilidad, se cumple en el círculo que vuelve sobre sí mismo a los efectos de mantener la eterna repetición del devenir en un grado de diferenciación siempre mayor. Así es como la naturaleza orgánica repite la inorgánica a una "potencia superior" (Schelling 1996, p. 177), y el espíritu reflexiona sobre ambas.

La posición subjetiva de la naturaleza le permite a Schelling abandonar el modelo mecanicista de la naturaleza por una física especulativa, cuyo sujeto consiste en la unidad dinámica, ideal y autoorganizada del devenir natural. La subjetividad de la naturaleza expresa su carácter productivo, autónomo y autosuficiente, al cual remite hoy el pensamiento ecofilosófico, ecofeminista y posthumano. El hecho de que la naturaleza sea sujeto incondicionado de su propia posición y despliegue expresa en otros términos su libertad creadora, libertad que es en última instancia el concepto especulativo por antonomasia de la tradición romántico-idealista.

La libertad schellingiana no se refiere a una propiedad volitiva del sujeto racional, claro y distinto, capaz de elegir entre diversas representaciones del bien, sino a la reflexión inmanente del poder, por cuya decisión traspasa de lo virtual a lo actual, de lo posible a lo efectivo. La potenciación efectiva de lo infinitamente posible es libertad en acto -tal como lo recogerá el existencialismo posterior-, y de aquí que Schelling la defina como "el último acto potenciador gracias al cual toda la naturaleza se transfigura en sensación, en inteligencia, y finalmente en voluntad" (Schelling 1989, p. 147; 1996, pp. 247-48). El devenir constituye en este sentido el progreso de la libertad hacia sí misma, su ascenso desde el fondo oscuro de lo infinitamente posible a la transparencia espiritual en la cual la existencia se reconoce a sí misma. En su último acto potenciador, el en-sí negativo del fundamento se revela como "el único posible concepto positivo del en-sí" (1989, p. 49), vale decir, autodeterminado.

\section{La concepción de lo naciente}

Si hay una categoría que le permitió a Schelling superar el paradigma abstracto de un Logos trascendente y perfecto por la inmanencia material del fundamento oscuro y caótico, tal es la categoría de nacimiento -Geburt-: dinamismo primero y ejemplar 
de una apertura expansiva - $\chi \alpha \omega s-$ que es a la vez par(t)ición original. Schelling transforma el nacimiento en una categoría especulativa -estrictamente conceptual y conceptiva - a través de la cual articula el monismo del Uno Infundado con la dialéctica diferencial del dar a luz. De la oscuridad primigenia a la diferencia de lo nuevo media el nacimiento como repetición reflexiva del origen en su propia negación.

Schelling le debe a Jacob Böhme -y en él a la tradición mística alemana- el concepto de nacimiento divino: "esa eterna rueda del nacer de Dios" (Böhme 1992, p. 464) en la que continuamente gira el mundo. La relevancia de esta categoría para Schelling es tal que a ella le atribuye el comienzo del pensamiento moderno (Schelling 1998, p. 138), es decir, el pasaje de la trascendencia actual a la inmanencia potencial del absoluto. La rueda del nacimiento - círculo o huevo cósmico (Schelling 2002, p. 196)- expresa la duplicidad de un movimiento inmanente, que empieza y concluye en sí mismo, y que por lo tanto se mantiene él mismo deviniendo radicalmente otro. Nacer es tanto ex-ponerse y ex-sistir afuera (Nancy 1993, p. 4), par(t)irse, como "inexistir" (Sloterdijk 2003, p. 548) en la repetición del origen devenido medio y elemento de vida. En la contradicción de un caos primitivo abierto a la alteridad y el parto de una alteridad remitida al origen, allí se produce, en un instante, el nacimiento eterno.

La categoría especulativa del nacimiento contiene algunas determinaciones que vale la pena repasar. En primer lugar, la determinación de la inmanencia radical, toda vez que nacer significa "venir-de-dentro" (Sloterdijk 2003, p. 300), surgir de la intimidad potencial por su propio desdoblamiento. El nacimiento es por eso una categoría divina que expresa la acción de Dios sobre sí mismo, su conversión reflexiva y transitiva a la alteridad, o bien, la decisión de existir en tanto que otro. En consecuencia, el nacimiento comporta una reflexión negativa, la contra-acción, vaciamiento o negación potencial de Dios en la que son paridos el tiempo y lo finito. Se trata asimismo de una categoría de la libertad que Schelling describe como un proceso voluntario y desiderativo, fruto de esa "ansia-Sehnsucht-que siente el Uno eterno de engendrase a sí mismo" (1989,pp. 167,253). La libertad salva a Dios de la disolución panteísta y a la creación del fatalismo. Por su olvido, Schelling le achaca a Böhme el haber convertido a la divinidad en la sustancia inmediata del mundo y a lo finito en el inexorable destino de la esencia eterna (Schelling 2007b, pp. 175-77). Además, nacer supone partición y parición, esto es, un desdoblamiento que escinde, opone y tensiona las fuerzas de lo real.

En última instancia, la categoría del nacimiento está determinada por la oscuridad inicial -noche, caos abierto, seno cósmico, caverna de sombras, indeterminación y posibilidad puras- que da a luz. Lo oscuro guarda el secreto de la creación, entreteje sus fibras y espera con paciencia la maduración de la obra. "Todo nacimiento explica Schelling- es un nacimiento desde la oscuridad a la luz; la semilla ha de ser hundida en la tierra y morir en las tinieblas a fin de que pueda alzarse una forma luminosa más hermosa y desarrollarse bajo los rayos del sol. El hombre se forma en el seno materno y solo desde la oscuridad de lo que carece de entendimiento (del sentimiento y el ansia, maravillosa madre del conocimiento) nacen los pensamientos luminosos" (Schelling 1989, p. 169). Metonimia universal, nacer se convierte para Schelling en el nombre propio del devenir, toda vez que éste acontece en los términos de una progresión ascendente de lo posible a la siempre mayor diferenciación de la existencia. 
Nacimiento, oscuridad, caos abierto, madre y fiera materia restituyen la mítica primordial de la vieja Europa pre-indoeuropa e hilozoista. De ese sustrato vitalista procede otra de las grandes figuras teogónicas del romanticismo, a saber, Dionisio: ese hijo nocturno y sacrificial de la Diosa en quien religiones matriciales arcaicas celebraban el eterno renacimiento de la vida (Dietrich 1974, pp. 116-117; Baring y Cashford 2005). Dionisio, el dios orgiástico y lunar, báquico delirio de un éxtasis creador, él es quien nace de esa eterna rueda divina y cuyo nacimiento trae la esperanza de un futuro transformador. Se entiende entonces por qué los amigos del Seminario de Tubinga lo escogieron como mito especulativo de la revolución en la novedad de su renacimiento espiritual (Safranski 2009, p. 148; Frank 1994, p. 22).

Pero paradójicamente, porque todo nace de su misma contradicción, lo engendrado no resiste el tiempo y espacio de la separación y termina finalmente por volver a la noche del origen, ese pre-tiempo de infinitas posibilidades. Seno y tumba, acción y contra-acción, generación y destrucción son, en su identidad absoluta, mutuo destino. La imagen del instante que Schelling le aplica a la libertad, también vale para el nacimiento, ese otro "relámpago de la eternidad que disipa las tinieblas de este mundo, pero que en su acción es inmediatamente devorado por sí mismo" (Schelling 2015, p. 97). El instante de alumbramiento paga así el precio de su separación.

Así como hay un ansia originaria de dar a luz, hay también una atracción infinita de la noche misteriosa y su potencia absoluta. Ella guarda la ambigüedad de todo misterio: esa terrible fascinación, tan horrible y espantosa como mayestática e imponente. Atrae por la fuerza de su poder infinito, que todo lo puede. Esa potencia en la que el nacimiento se desdobla a sí mismo no es sino "la fuerza universal [allgemeine], interminable de la muerte" (Schelling 2015, p. 89). Misterio Unheimlich-por antonomasia, la muerte hace girar la rueda eterna de nacer y su pulsión, para decirlo con Freud, marca el paso de la vida.

La concepción de lo naciente solo se cumple en esa vuelta sobre sí misma que la iguala con la muerte. En un instante, como un relámpago, la infinita potencia de lo negativo alcanza el punto cero del origen para volver a parirse una y otra vez. Porque en el principio es la oscuridad abisal de una nada menos-que-nada, la existencia deviene ese báquico delirio de la negatividad radical.

\section{A modo conclusivo}

El supuesto de una feminización de la filosofía a través de la cual el primer romanticismo alemán desafía la tradición metafísica del antiguo régimen, hace visible la tácita sexuación del discurso filosófico, nuevo y viejo. El clásico faloLogos-centrismo se desfonda en un nuevo orden especulativo que eleva el ideal de la libertad a sujeto ontológico absoluto e incondicionado, cuyas derivas políticas continúan alimentando el proyecto siempre inconcluso de la Revolución. Si el falogocentrismo clásico significó la trascendencia perfecta del Acto inmutable y luminoso, dualistamente separado del universo finito y contingente, el nuevo régimen especulativo instituye la inmanencia radical de lo infinitamente posible, abierta por la contra-acción reflexiva de lo absoluto sobre sí mismo.

El pensamiento de Schelling ofrece una síntesis privilegiada de la transmutación especulativa, la femeninización ontológica y la restitución mítico-conceptual del hilozoísmo primitivo propias de la modernidad romántico-idealista. El paso decisivo 
de su pensamiento consistió en abrir lo absoluto al caos vacío de su fecundidad, vale decir, convertirlo en seno fecundo y ansioso por dar a luz. Para Schelling, en el origen es la oscuridad del caos, cuya apertura es partición y nacimiento. La superación del paradigma del Acto puro, acabado y perfecto, se produce así en virtud de una potencia infinita que opera recíprocamente la fundación y des-fundación de lo real, su actualización y contingencia. La primacía de la potencia instituye eo ipso un origen reflexivo y dialéctico, resuelto en la continuidad del devenir. Inmanencia, negatividad y repetición constantemente potenciada serán así las nuevas categorías de la analítica del devenir schellingiano, siempre en progreso hacia sí mismo.

Con Schelling, y en particular con su así llamada filosofía positiva, vuelve la mítica de la conciencia arcaica y matricial, cuando el origen era seno y tumba, huevo cósmico, rueda, círculo de los círculos, noche infinita, indómita materia, oscuridad abisal en cuya caverna nacen dioses y hombres. En esa retracción de la conciencia a su imaginario primitivo reside el comienzo de los tiempos modernos así como el futuro mismo del pensamiento schellingiano, del cual hoy abrevan los nuevos materialismos y vitalismos, las eco-filosofías, el psicoanálisis, el neo-existencialismo y el pensamiento feminista, en la certeza de una negatividad radical que quiebra todo intento de totalización.

Si el giro copernicano de Kant ya había abandonado la heteronomía del conocimiento y la moral, el giro romántico nos despierta para siempre del dogmatismo falogocéntrico a fin señalarnos ya no lo que es o debería ser, sino lo que siempre quiere y puede existir.

\section{Referencias bibliográficas}

Albizu, E. (1995): “Poetizar y pensar. La metáfora 'noche’ y la inhibición intrínseca de la razón especulativa", Philosophia, pp. 61-81.

Assiter, A. (2015): Kierkegaard, Eve and Metaphors of Birth, London \& New York, Rowman \& Littlefield.

Baring, A. y Cashford, J. (2005): El mito de la diosa, Madrid, Ediciones Siruela.

Binetti, M. J. (2019): "La avanzada material del viejo idealismo", Pensamiento. Revista de Investigación e Información Filosófica, 75/284, pp. 701-716.

Binetti, M. J. (2018): Mater/realismo. Aportes para una filosofia feminista de la diferencia sexual, Buenos Aires, Prometeo.

Binetti, M. J. (2015): El idealismo de Kierkegaard, México, Universidad Iberoamericana.

Böhme, J. (1992): Aurora, Frankfurt am Main und Leipzig, Gerhard Wehr. Insel.

Carrasco-Conde, A. (2019): "Fundamental Perspectives: Simulacra, History and the Influence of Schelling in contemporary Thought", International Journal of Zizek Studies, 10/3, pp. $1-20$.

Dietrich, B. C. (1974): The origins of Greek Religion, Berlin \& New York, Walter de Gruyter. Fenichel, T. (2019): Schelling, Freud, and the Philosophical Foundations of Psychoanalysis. Uncanny Belonging, London \& New York, Routledge.

Frank, M. (1994): El Dios venidero. Lecciones sobre la Nueva Mitología, Barcelona, Ediciones del Serbal.

Grant, I. H. (2006): Philosophies of Nature after Schelling, New York, Continuum.

Gratton, P. (2014): Speculative Realism. Problems and Prospects, Bloomsbury, London \& New York, Bloomsbury. 
Holland-Cunz, B. (1996): Ecofeminismos, Madrid, Ediciones Cátedra.

Hölderlin (2009): Poesía completa, 2 vols., trad. Federico Gorbea, Barcelona, Ediciones 29.

Kierkegaard, S. (2000): De los papeles de alguien que todavía vive. Sobre el concepto de la ironía, trad. Begonya Saez Tajafuerce y Darío González, Madrid, Trotta.

Nancy, J.-L. (1993): The Birth to Presence, Stanford, Stanford University Press.

Norman, J. y Welchman, A. (2004): The new Schelling, London \& New York, Continuum.

Novalis (2007): Notes for a Romantic Encyclopaedia Das Allgemeine Brouillon, ed. David W. Wood, New York, SUNY.

Novalis (1971): Himnos a la noche. Cantos espirituales. Otros poemas, Buenos Aires, Ediciones del Mediodía.

O' Neill Burns, M. (2016): "Vitality or Weakness", Angelaki. Journal of Theoretical Humanities, 21/4, pp. 11-22.

Safranski, R. (2009): Romanticismo. Una odisea del espíritu alemán, Barcelona, Tusquets Editores.

Schelling, F. W. F. (2015): Clara. Un diálogo sobre la muerte, Santiago de Chile, Editorial Universitaria.

Schelling, F. W. F. (2007a): Historical-Critical Introduction to the Philosophy of Mythology, New York, State University of New York.

Schelling, F. W. F. (2007b): The Grounding of positive Philosophy. The Berlin Lectures, New York, State University of New York.

Schelling, F. W. F. (2005): Sistema del idealismo trascendental, Madrid, Anthropos.

Schelling, F. W. F. (2002): Las edades del mundo, Madrid, Akal.

Schelling, F. W. F. (1999): Filosofía del arte, Madrid, Tecnos.

Schelling, F. W. F. (1998): Filosofia de la Revelación, Pamplona, Cuadernos de Anuario filosófico 51, Universidad de Navarra.

Schelling, F. W. F. (1996): Escritos sobre filosofía de la naturaleza, Buenos Aires, Alianza.

Schelling, F. W. F. (1989): Investigaciones filosóficas sobre la esencia de la libertad humana y los objetos con ella relacionados, Barcelona, Anthropos.

Schlagdenhauffen, A. (1934): Frédéric Schlegel et son groupe. La doctrine de l'Athenaeum (1798-1800), Paris, Les Belles Lettres.

Schlegel, F. (2007): Lucinda, trad. María J. Pacheco, México, Siglo Veintiuno Editores.

Schlegel, F. (1994): Poesía y Filosofía, trad. Diego Sánchez Meca, Madrid, Alianza.

Schulte-Sasse, J. (1997): Theory as Practice. A Critical Anthology of Early German Romantic Writings, Minneapolis \& London, University of Minnesota Press.

Sloterdijk, P. (2003): Esferas I. Burbujas. Microesferología, Madrid, Siruela.

Stone, A. (2018): Nature, Ethics and Gender in German Romanticism and Idealism, London \& New York, Rowman \& Littlefield.

Wirth, J. M. (2005): Schelling Now. Contemporary Readings, Bloomington \& Indianapolis, Indiana University Press.

Woodard, B. (2013): "Schellingian Thought for Ecological Politics", Anarchist Developments in Cultural Studies, 2, pp. 86-108.

Žižek, S. (2017): Incontinence of the Void. Economico-Philosophical Spandrels, Cambridge $\&$ London, The MIT Press.

Žižek, S. (2014): Absolute Recoil. Towards A New Foundation of Dialectical Materialism, London \& New York, Verso.

Žižek, S. (1997): Abyss of Freedom. Ages of the World, The University of Michigan Press. 